\title{
Modifiable workplace risk factors contributing to workplace absence across health conditions: A stakeholder-centered best-evidence synthesis of systematic reviews
}

\author{
Marc White ${ }^{\mathrm{a}, *}$, Shannon Wagner ${ }^{\mathrm{b}}$, Izabela Z. Schultz ${ }^{\mathrm{c}}$, Eleanor Murray ${ }^{\mathrm{d}}$, Susan M. Bradley, \\ Vernita $\mathrm{Hsu}^{\mathrm{f}}$, Lisa McGuire ${ }^{\mathrm{g}}$ and Werner Schulz ${ }^{\mathrm{h}}$ \\ ${ }^{a}$ Department of Family Practice, University of British Columbia, Vancouver, BC, Canada \\ ${ }^{\mathrm{b}}$ School of Health Sciences, University of Northern British Columbia, Prince George, BC, Canada \\ ${ }^{\mathrm{c}}$ Department of Educational and Counseling Psychology and Special Education, University of British Columbia, \\ Vancouver, BC, Canada \\ ${ }^{\mathrm{d}}$ Epidemiologist, Vancouver, BC, Canada \\ ${ }^{\mathrm{e}}$ Information Resource Consultant, Vancouver, BC, Canada \\ ${ }_{\mathrm{f}}^{\mathrm{f}} B C$ Construction Safety Alliance, New Westminster, BC, Canada \\ ${ }^{\mathrm{g}}$ The FIOSA-MIOSA Safety Alliance of BC, Chilliwack, BC, Canada \\ ${ }^{\mathrm{h}}$ Healthcare Benefit Trust, Vancouver, BC, Canada
}

Received 15 November 2012

Accepted 24 January 2013

\begin{abstract}
.
BACKGROUND: A challenge facing stakeholders is the identification and translation of relevant high quality research to inform policy and practice. This study engaged academic and community stakeholders in conducting a best evidence-synthesis to enhance knowledge use.

OBJECTIVES: To identify modifiable workplace disability risk and protective factors across common health conditions impacting work-related absence.

METHODS: We searched MEDLINE, Embase, CINHAL, The Cochrane Library, PsycINFO, BusinessSourceComplete, and ABI/Inform from 2000 to 2011. Systematic reviews that employed quantitative, qualitative, or mixed methods of work-focused population were considered for inclusion. Two or more independent reviewers reviewed titles only, titles and abstracts, and/or full articles when assessing eligibility for inclusion. Selected articles underwent methodological screening.

RESULTS: The search strategy, expert input and grey literature identified 2,467 unique records from which 142 full text articles underwent comprehensive review. Twenty-seven systematic reviews met eligibility criteria. Modifiable work factors found to have consistent evidence across two or more health conditions included lack of social support, increased physical demands at work, job strain, lack of supervisory support, increased psychological demands, low job satisfaction, low worker control of job, and poor leadership quality.
\end{abstract}

\footnotetext{
* Address for correspondence: Marc White, c/o Canadian Institute for the Relief of Pain and Disability, \#204-916 W. Broadway, Van-
}

couver, BC V5Z 1K7 Canada. Tel.: +1 604684 4148; Fax: +1 604 684 6247; E-mail: Marc.White@familymed.ubc.ca. 
CONCLUSIONS: The active engagement of stakeholders led to greater understanding of relevance of the study findings for community stakeholders and appreciation of the mutual benefits of collaboration.

Keywords: Disability prevention, risk and protective factors, occupational health, workplace absence

\section{Introduction}

Workers presenting with common chronic diseases and injuries accompanied by workplace absence, prolonged disability, and associated costs, pose significant burden to workers, employers and society [13]. In particular, direct costs may include lost-time wage replacement, health care provider expenses, investigative tests, hospitalizations, surgeries, and disability settlements and pensions [4]. Indirect costs may include loss of work productivity, training of replacement workers, administrative expenses, spillover effects on coworkers, supervisors and families and lost tax revenue for governments [4]. In addition to organizational expenses, negative consequences for workers and families may include lost wages, pain, suffering, activity limitations, and impacts on future employability [4]. Given the serious potential impact of workplace absence and prolonged disability duration, it is important to better understand modifiable workplace factors that may be contributing to unnecessary work absence and prolonged disability. Therefore, our primary purpose for the present systematic review was to provide meaningful and easily interpretable information regarding workplace factors that may be conducive to modification, and subsequently, to reduction of workplace disability.

Public and private sector employers in North America and other western industrialized nations share growing concerns about an apparent "disability epidemic" that includes increasing disability costs associated with work absenteeism and presenteeism [5,6]. Further, the literature points to a rising prevalence of chronic disability in the population $[7,8]$ that has been linked to reduced work productivity [5,9]. Despite the fact that rigorous scientific studies show that such workplace absences, injuries and associated disabilities are often preventable [6,10-19], in 2006 Canadian workers' compensation boards disbursed $\$ 8.7$ billion for workplace injury, not including work-absences from chronic diseases $[2,20]$. At this time, the full reasons for this apparent disconnect between knowledge and action are not entirely clear. However, it is clear that prevention requires collaborative action by many workplace stakeholders who play different roles within the worksite and the broader community; these stakeholders include government policy makers, insurers, unions, health professionals, business leaders, managers and supervisors [10-12].

\subsection{Academic and community partnership}

From our discussions with stakeholders during the planning phase of this study, it was clear that workplace practitioners were motivated to learn from current research but found the literature difficult to translate into practical solutions, lacked access to relevant research articles, and required expert assistance in critical appraisal of the evidence (assessing scientific merit) [15]. As a result, we fully engaged workplace stakeholders in the research process so that primary knowledge consumers were given the opportunity to guide the usefulness of the resulting data. Importantly, the role of the worksite stakeholders was not as participants, as is often the case; rather, the workplace stakeholders in this study were included as full research partners. In this way, the workplace stakeholders created the categories for data interpretation and highlighted challenges regarding previous data utility.

With respect to specific concerns regarding translating research into best practice, a common challenge expressed by stakeholders was the identification of high quality research, and subsequent translation into useful information to inform policy, training and practice. Stakeholders were also concerned about the lack of integration of knowledge concerning work absences across general health conditions. There are a growing number of primary studies and systematic reviews identifying factors that address workplace absence with respect to specific health conditions; however, stakeholders were specifically interested in creating informed policies and principles relevant across a variety of common health conditions. Currently, there is a lack of integration of research regarding modifiable disability predictors that apply to many, rather than only to highly specific health conditions. In general, our process suggested that stakeholders are seeking more integrative synthesis approaches to inform and create generalized principles and recommended practices intended for the prevention of disability. 
In order to address stakeholder concerns and apparent gaps in the literature, the present synthesis was created by an academic community partnership (ACP) involving researchers from different fields and disciplines at three British Columbia (BC) Canada universities and the engagement of three community partners. The community partners represented two occupational health and safety organizations and a not-for-profit health and welfare trust that administers group health and welfare benefits for over 100,000 employees in the health care and social services sector in BC. Academiccommunity partnerships (ACPs) have been used with varying degrees of success as a mechanism for facilitating knowledge-to-action (K2A) [21-25]. However, research investigating ACPs has found that these collaborations often suffer from complex conceptual, definitional, methodological, and translational issues that inevitably lead to questions about their scientific merit and societal value [26-29]. To address some of these challenges, the current ACP defined roles, responsibilities and key tasks, and created specific workflows to systematize the identification, prioritization and translation of high quality research.

Through an iterative process of problem identification and clarification, ACP deliberations led to a decision to conduct a stakeholder-centered review of systematic reviews to identify disability risk and protective factors associated with work-related and chronic disease health conditions that impact on work-related absences and disability duration. The present article reports the process and findings of the synthesis related to modifiable risk and protective workplace factors.

\section{Methods}

\subsection{Partnership process}

Using an iterative systematic process involving faceto-face meetings, videoconferencing, review and reflective input regarding meeting minutes, workflows and surveys, stakeholders and academic researchers participated in defining the purpose of the systematic review. This process included identification of search terms, review of scoping search results to refine inclusion and exclusion criteria, development and validation of an abstraction process to ensure that contextually relevant data, discussion of findings, creation of evidentiary table categories, and report presentation considerations were being appropriately captured.

To identify stakeholder-relevant systematic reviews we circulated and sought input on keywords, and con- ducted a series of pilot searches providing examples of literature found. This initial process assisted us in reviewing search terms used in relevant studies, led to refining the research question, and resulted in the development of stakeholder-centered appropriate inclusion/exclusion criteria that informed the final search strategy. During the pilot search process, the translation of MeSH terms (structured language for Medline) and keywords across other databases were reviewed by one or more external librarians with expertise in health sciences, social sciences and business databases.

\subsection{Inclusion/exclusion criteria}

Our inclusion criteria were systematic reviews that included adults (aged 15+ years) and a work-focused population (i.e. working or attempting to secure work); all systematic reviews that employed quantitative metaanalyses, qualitative meta-analyses, and non-metaanalytic systematic reviews of both qualitative and quantitative literature were considered for inclusion. Further, systematic reviews considered for inclusion were required to address work absence related to workers presenting with personal illness, health condition, or illness as an outcome, including physical and/or mental conditions, and also were required to discuss predictive factors of work absence. Our exclusion criteria included reviews where the primary illness was a severe physical, mental and/or extremely rare condition, or reviews that focused on a specific occupation that may be less generalizable including air traffic controllers, fire fighters or police. Systematic reviews focused only on interventions, with no discussion of risk or protective factors were also excluded.

\subsection{Search strategies}

All search strategies were originally written by an information specialist and were reviewed by one or more of her peers. Search results were uploaded to RefWorks and then exported to Excel. Removal of duplicate results was completed manually. Other sources of records included scoping searches, expert input, grey literature searches of health-evidence.ca, Rehab+, National Rehabilitation Information Center (NARIC), and Institute of Work and Health (IWH). Hand-searching of the proceedings of a relevant conference (found in the EMBASE search) was also completed. After the initial search results were reviewed, the MEDLINE search strategy was reviewed and modified by a second information resource officer to simplify logic and ensure congruency with search terms. A copy of the search strategy is available upon request. 


\subsection{Evaluation of quality and relevance}

Methodological quality of eligible studies was evaluated using principles and procedures congruent with recommendations discussed in The PRISMA Statement and the Institute of Medicine's Standards for Systematic Reviews [30]. This included (i) use of multiple information resource people, researchers and stakeholders in the development of the search strategy, (ii) pilot-testing the search strategy to identify stakeholderrelevance of articles, search terms used in relevant retrieved articles, (iii) validation procedures to assess comprehensiveness of the MEDLINEsearch strategy, (iv) assessing retrieved titles and abstracts for relevance, (v) selecting articles for more in-depth review, (vi) obtaining full text copies of these potentially eligible reviews, and assessing these reviews for relevance and quality (using independent assessment by at least two members of the review team), (vii) pilot testing abstraction process (for relevance and comprehensiveness) with stakeholders, and (viii) attention to the production of a final report relevant to stakeholders' needs and organizational contexts.

The original methodological criteria were based on a quality assessment tool developed by researchers at McMaster University for Health-evidence.ca, a website supporting knowledge translation relevant to public health nursing. Researchers compared the original criteria with EBM Glasgow Checklist for Systematic Reviews, and assessed for congruency with AMSTAR methodological quality recommendations for critical appraisal of systematic reviews [31]. Methodological criteria were reviewed and refined by the ACP using a process of sharing (email distribution), discussion, reflection and consensus. Changes were made in scoring and standardizing questions across quantitative, qualitative and mixed methodological criteria (see Table 1).

During the scientific review process, the following additional questions/issues were asked of reviewers: applicability to small employers, research design strengths/weaknesses, implementation recommendations from authors, implementation recommendations from reviewers, and whether the systematic review met the inclusion/exclusion criteria for this study.

\subsection{Data abstraction}

A set of preliminary data abstraction formats were prepared by the research associate, and were reviewed and modified by two researchers before circulation to ACP members. The data abstraction forms deve- loped consisted of Researcher Tables (Methods Results, Conclusions) and Stakeholder Synthesis Tables (Worker/Workplace Factors categorized by Modifiable and Non-Modifiable factors); the present article addresses workplace factors only. Following initial discussions with stakeholders it was decided to pilot the abstraction forms by having the research associate abstract findings from 10 relevant articles. Stakeholders were provided with copies of articles and asked to select two or more articles of interest that could be used to assess whether the data abstraction was missing relevant findings.

An initial categorization of findings was developed by the research associate following agreed upon concepts in the data abstraction forms. Once the abstraction tables were $90 \%$ complete, stakeholders were invited to reconsider the initial categorization of factors; according to discussion and consensus, this reconsideration led to significant changes in the placement and naming of psychosocial and mental health factors. Subsequent to abstraction of the data into table format, the table data was translated into meaningful factor-level themes as presented in the results.

\section{Results}

\subsection{Search results}

There were 2,467 unique records identified and 142 full text articles reviewed. Thirty-six systematic reviews (quantitative, qualitative and mixed) met our eligibility criteria and methodological quality review for risk and protective factors associated with workplace absence. These findings were segmented into modifiable and non-modifiable factors, and whether they addressed individual factors or organizational factors. A subset of 27 systematic reviews of this overall search strategy addressed workplace factors. As shown in Table 2, the 27 studies that met the synthesis inclusion criteria varied considerably in sample characteristics and size, data sources, and outcome measures.

\subsection{Validation of search strategy}

Records of database search strategies, de-duplication, other sources searched, and exclusions were recorded in VonVille's "Excel workbook to track systematic review search results" [32] and the final PRISMA flowchart [33] (Fig. 1) was generated using this workbook. Validation of the search strategy was performed 
Table 1

Methodological quality review

\begin{tabular}{|c|c|c|}
\hline \multicolumn{3}{|l|}{ Common criteria for both qualitative and quantitative methodological review } \\
\hline Question & Answer choice & Score \\
\hline \multirow[t]{2}{*}{ Did the authors have a clearly focused question? } & Yes & 1 \\
\hline & No & 0 \\
\hline \multirow[t]{3}{*}{ Were inclusion/exclusion criteria used? } & Yes & 1 \\
\hline & No & 0 \\
\hline & Not specified & 0 \\
\hline \multirow{3}{*}{$\begin{array}{l}\text { Did the authors describe a search strategy that was comprehensive and } \\
\text { reproducible? }\end{array}$} & Yes & 1 \\
\hline & No & 0 \\
\hline & Not specified & 0 \\
\hline Please click the search strategies used & (selected/unselected) & $\begin{array}{l}\text { a. Five or more databases: } 2 \\
\text { b. Two to four databases: } 1 \\
\text { c. One database: } 0\end{array}$ \\
\hline \multirow[t]{2}{*}{ Did search strategy cover an adequate number of years? $(10+$ years $)$} & Yes & 1 \\
\hline & No & 0 \\
\hline \multirow[t]{2}{*}{ Does the data support the author's interpretation? } & Yes, mostly & 1 \\
\hline & No & 0 \\
\hline \multirow[t]{2}{*}{ Are there any concerns related to COI? } & Yes & 0 \\
\hline & No & 1 \\
\hline \multicolumn{3}{|l|}{ Specific criteria quantitative methodological quality } \\
\hline Question & Answer choice & Score \\
\hline \multirow[t]{2}{*}{ Did the review assess the methodological quality of the primary studies? } & Yes & 1 \\
\hline & No & 0 \\
\hline \multirow[t]{4}{*}{ What methods did the authors use to combine or compare results across studies? } & Meta-analyses & 2 \\
\hline & Descriptive + quality weight & 2 \\
\hline & Descriptive no weight & 1 \\
\hline & Other & 0 \\
\hline \multirow{5}{*}{$\begin{array}{l}\text { How strong was the level of evidence supporting the strongest conclusions } \\
\text { of the study? }\end{array}$} & Level 1 (RCT) & 2 \\
\hline & Level 2 (non-random) & 1 \\
\hline & Level 3 (uncontrolled) & 0 \\
\hline & Unclear & 0 \\
\hline & & Total score possible: 13 \\
\hline \multicolumn{3}{|l|}{ Specific criteria qualitative and mixed methodological quality } \\
\hline \multicolumn{3}{|l|}{$\begin{array}{l}\text { Did the review assess the methodological quality of the primary studies? } \\
\text { (minimum of } 4 \text { ) }\end{array}$} \\
\hline$\square$ Suitability of methodology /paradigm to the research question & No & 0 \\
\hline \multicolumn{3}{|l|}{$\square$ Sampling (selection of participants/settings/documentation) } \\
\hline \multicolumn{3}{|l|}{$\square$ Clear description of context, data collection, and data analysis } \\
\hline \multicolumn{3}{|l|}{$\square$ Rigor (audit trail, some coding by 2 or more coders, deviant } \\
\hline \multicolumn{3}{|l|}{$\square$ Case analysis, respondent validation) } \\
\hline \multicolumn{3}{|l|}{$\square$ Triangulation } \\
\hline \multicolumn{3}{|l|}{$\square$ Reflexivity (researcher and research process) } \\
\hline \multicolumn{3}{|l|}{$\square$ Relevance (credibility, consistency, applicability, transferability) } \\
\hline \multirow{3}{*}{$\begin{array}{l}\text { Was this methodological quality review incorporated in the data analysis } \\
\text { (weighting of higher quality studies)? }\end{array}$} & Descriptive + quality weight & 2 \\
\hline & Descriptive no weight & 1 \\
\hline & Other & 0 \\
\hline \multirow{5}{*}{$\begin{array}{l}\text { How strong was the level of evidence supporting the strongest conclusions } \\
\text { of the study? }\end{array}$} & Level 1 (RCT) & 2 \\
\hline & Level 2 (non-random) & 1 \\
\hline & Level 3 (uncontrolled) & 0 \\
\hline & Unclear & 0 \\
\hline & & Total score possible: 13 \\
\hline
\end{tabular}

by re-running the final MEDLINE search updated to August 31, 2011. Of the final 36 included records (vide infra) for all factors (workplace, worker and societal factors), all had records in MEDLINE and 32 of these $(89 \%)$ were found using the final MEDLINE search. Of the final 27 records included in the subset for modifiable workplace factors, all had MEDLINE records, and 24 of these $(89 \%)$ were retrieved using the final MEDLINE search.

\subsection{Methodological quality criteria}

A weighted scoring system was created to address the quality of primary studies informing the systematic 


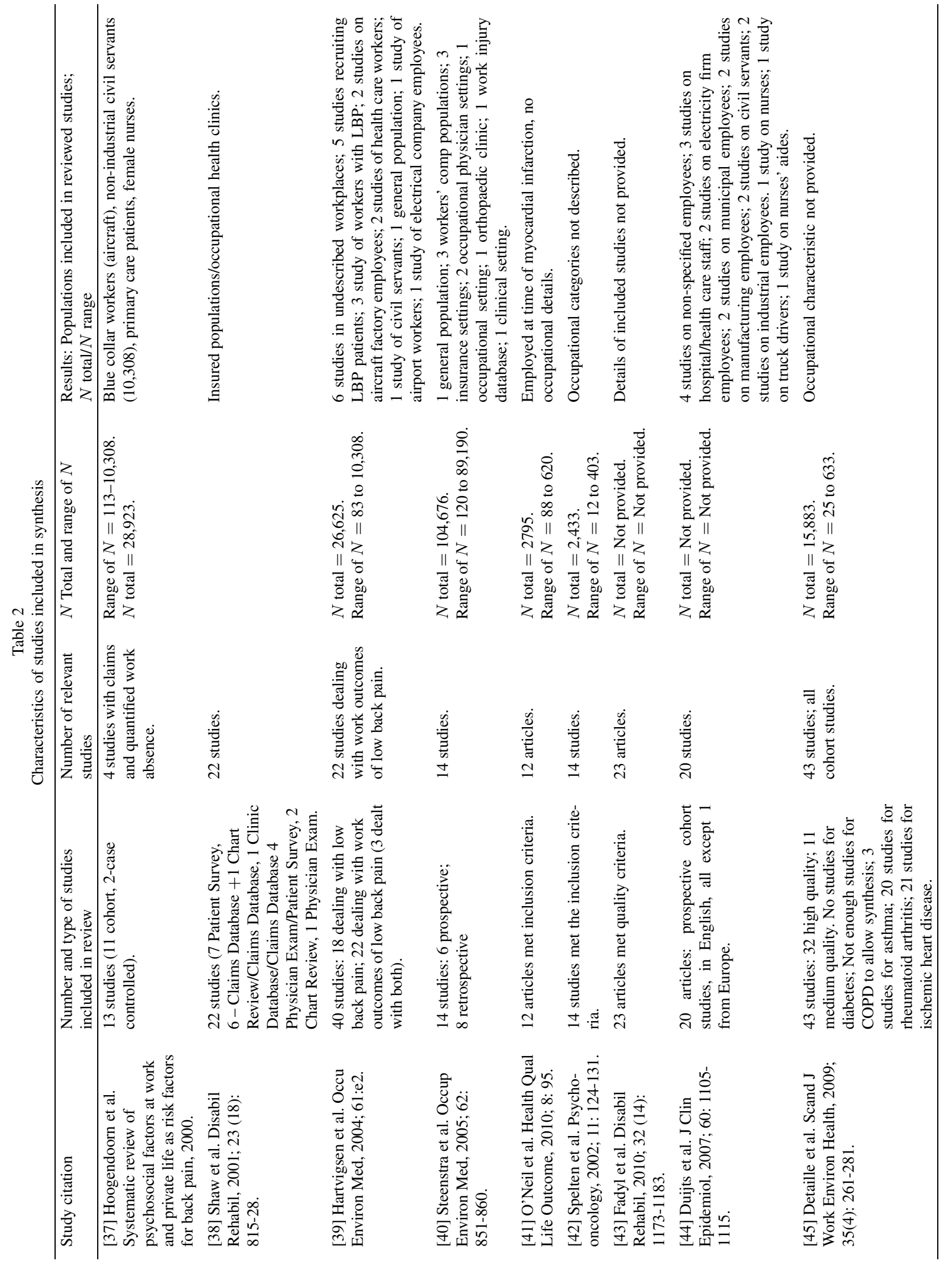



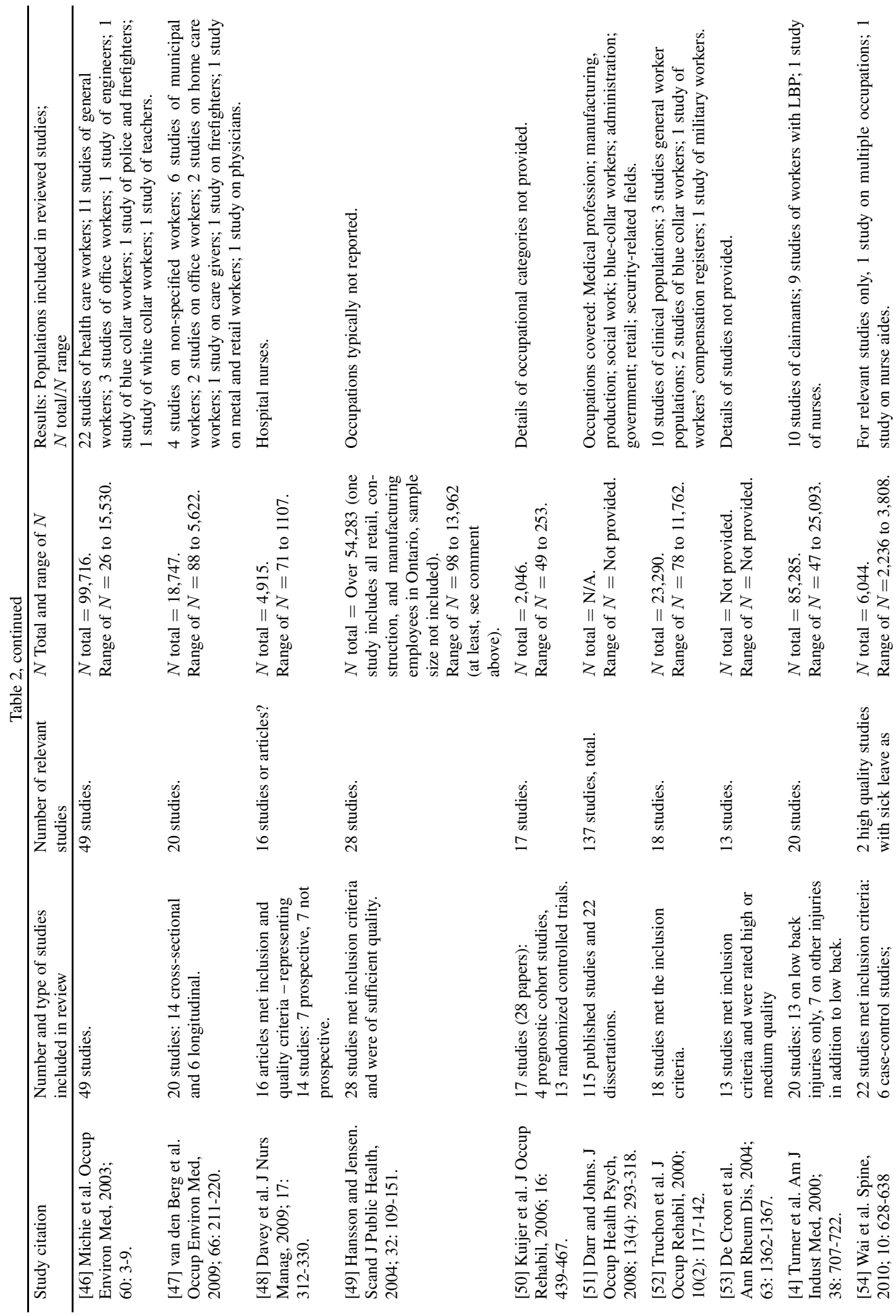

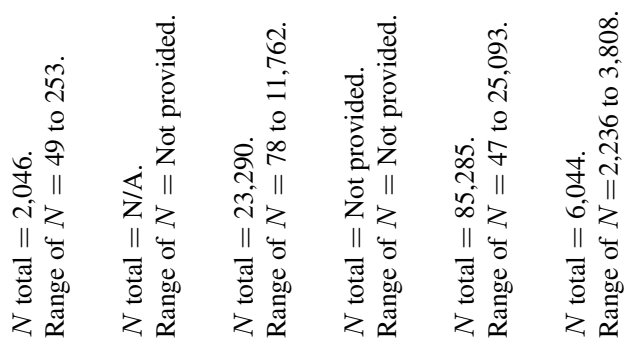

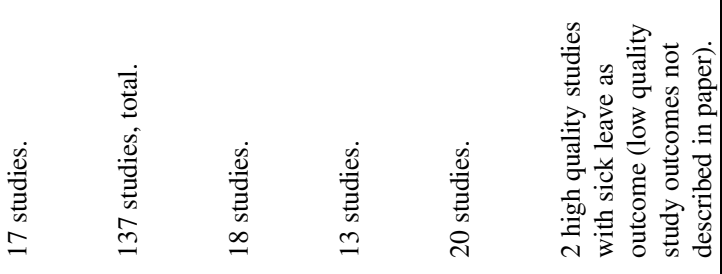

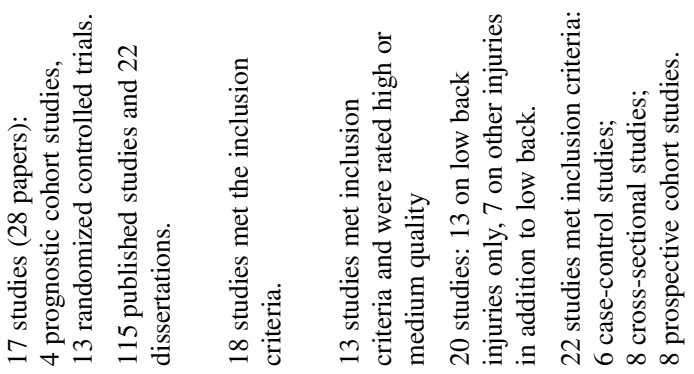

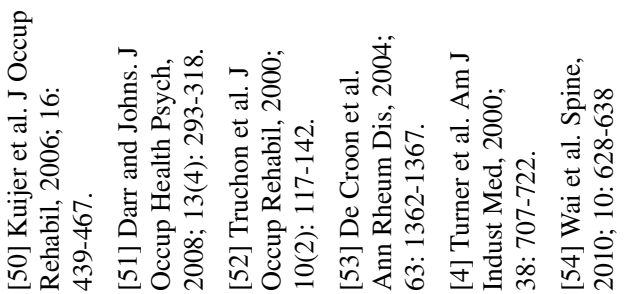




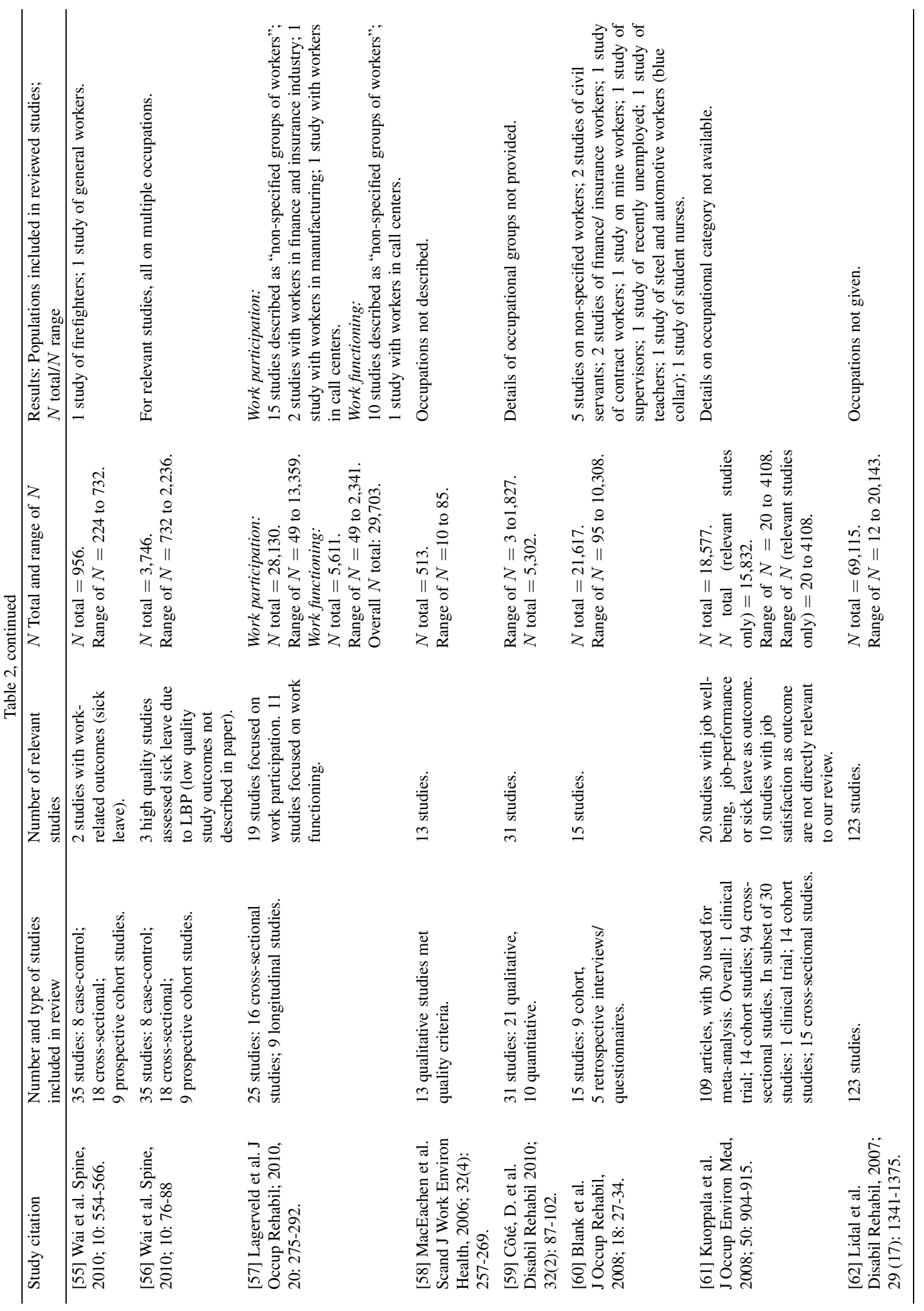




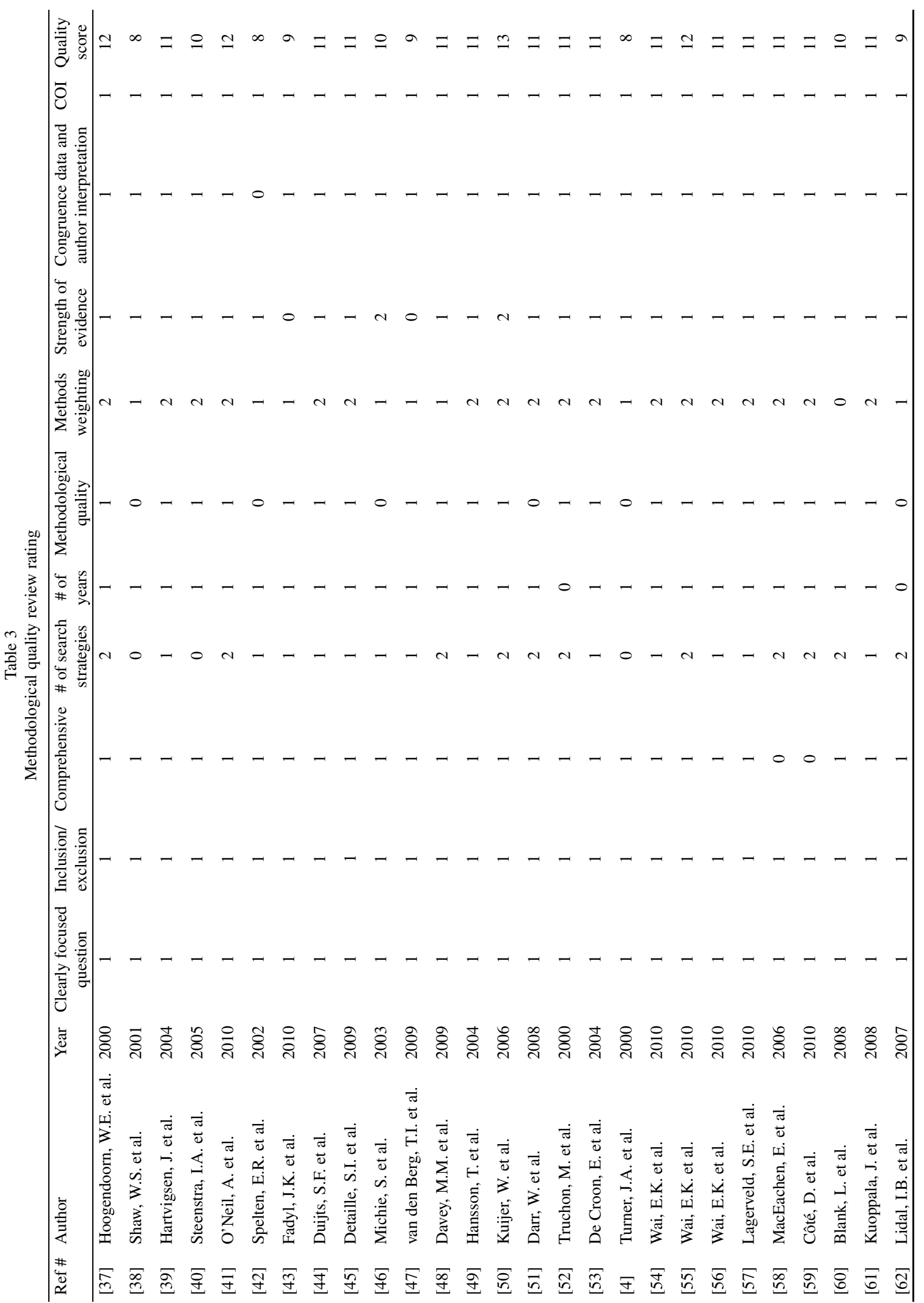




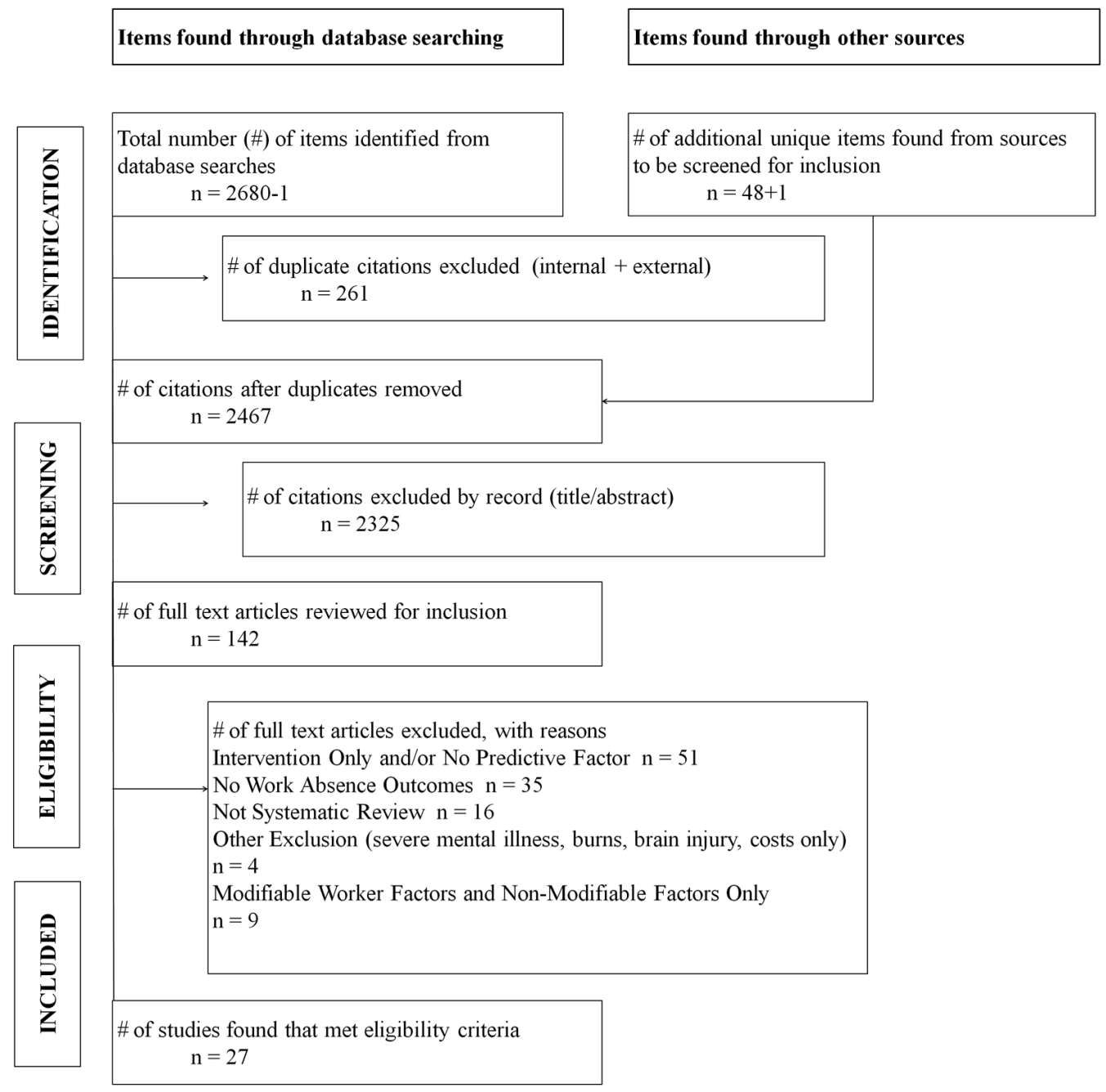

Fig. 1. Results of search strategy PRISMA chart.

review, as well as methods employed in combining and reporting results (see Table 3 ). The highest methodological score possible was 13 with the range of scores between eight and 13 (these scores were subsequently translated into percentages). Eighteen studies were considered higher methodological quality systematic reviews (greater or equal to $85 \%$ ), three were considered medium quality reviews (between $75 \%-84 \%$ ), and six were considered lower quality reviews (between 50-74\%). All 27 systematic reviews were deemed to be of sufficient quality to contribute to evidence synthesis, with some of the lower quality scores resulting from limitations of the quality of primary studies informing the respective synthesis. To assess inter-rater relia- bility, methodological results were downloaded into MS Excel from Fluid Surveys, with responses recoded to reflect the scoring system employed. Kappa statistics were used to calculate the chance-adjusted between-reviewer agreement and disagreements per item and number of responses between sets of reviewers. This was calculated using an online kappa calculator (http://justusrandolph.net/kappa/). The overall inter-rater reliability score for the synthesis of the original 36 articles was (0.752).

The studies included in the present analysis were heterogeneous in nature and precluded the use of metaanalysis as a primary method of evaluation. Bestevidence synthesis was therefore chosen to be our main method of critical appraisal [34,35]. Best-evidence 
Table 4

Level of evidentiary support across systematic reviews

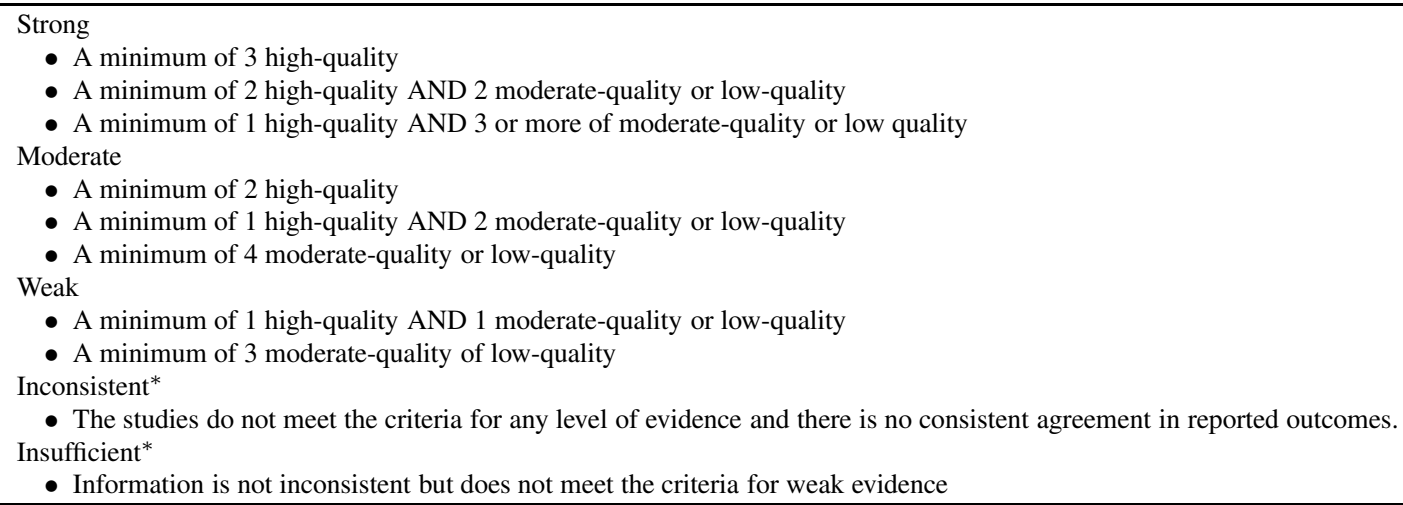

${ }^{*}$ The focus of this synthesis was the identification of risk factors, not the impact of interventions on work absence. Due to diversity of both clinical and occupational interventions and respective integrative conclusions, a summary statement cannot be made and thus evidence is labeled "inconsistent." However, factors identified in the included intervention studies may represent emerging or promising data for further investigation.

synthesis bases analysis on three aspect of evaluation: quality, quantity and consistency of available evidence [36]. Our results are reported based upon our team-developed evaluation model (see Table 4) indicating the fit with the criteria for a given factor in relationship to the methodological quality of the review. Importantly, this framework was discussed with the stakeholder members and reflected team perceptions and understanding regarding categorization and ranking of evidence. Effect size and/or assessment of variance were not able to be calculated across reviews given the different outcome factors, types of studies and level of reporting. Therefore, the terms strong, moderate, and weak are not indicative of the degree to which a given factor will influence the workplace; rather, they reflect the quality, quantity and consistency of each respective factor.

\subsection{Evidentiary support for modifiable workplace factors}

\subsubsection{Job factors}

\section{(a) Social support}

Seven systematic reviews considered the impact of social support on work disability. Two high-quality reviews and one low-quality review found moderate evidence that low co-worker support was associated with increased risk of work disability for workers presenting with low back pain $[37,38]$. However, one high quality systematic review by Hartvigsen et al. [39] found that, of the five high quality reviews included in their study, only two suggested a positive relationship between social support and consequences of low back pain. Steenstra et al. [40] provided a mid-quality review demon-
Table 5

Evidentiary support for modifiable workplace factors (strong, moderate, weak)

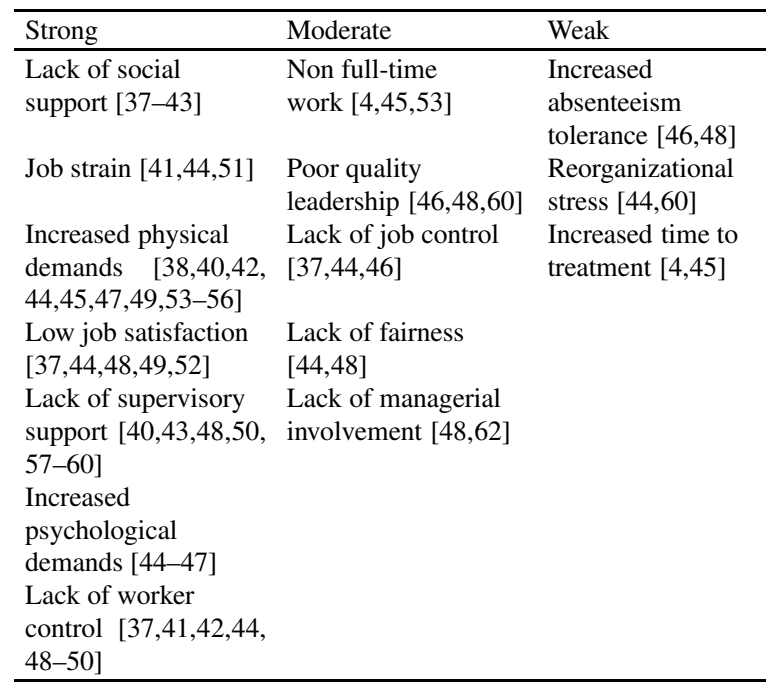

strating moderate evidence that higher co-worker support predicted increased likelihood for return to work for individuals with acute low back pain. Other reviews provided evidence of association, but did not overtly categorize the relationship. O'Neil et al. [41] provided a high-quality review that suggested a poor social network at work was associated with reduced work resumption after a cardiovascular event. Two lowerquality reviews also considered this relationship. Spelten et al. [42] found that positive co-worker attitude predicted more positive RTW outcomes for individuals with cancer. Similarly, Fadyl et al. [43] reported that more positive co-worker support and greater supervisory support were associated with increased work abil- 
ity for situations of work-related injury. There is strong evidence that a lack of social support in the workplace should be considered a predictor for work disability.

\section{(b) Psychological demand}

Four systematic reviews considered the impact of work characteristics on work disability. Two of these reviews were considered to be of high quality. Duijts et al. [44] reported limited evidence that high mental demands were associated with sick leave of more than three days (adjusted OR $=1.15$ ) for workers with psychosocial health concerns. Similarly, Detaille et al. [45] found moderate evidence that increased precision work predicted increased risk of work disability in workers with rheumatoid arthritis. These authors also found weak evidence that higher task complexity at work predicted increased work disability for the same group of workers. Michie et al. [46] provided a moderate-quality review that reported work demands (e.g., long hours, workload, pressure), monotonous work, role ambiguity, and job demands were associated with increased risk of sickness absence in individuals with psychological ill health. Finally, van den Berg et al. [47] provided a low-quality review with moderate evidence that greater mental demands at work predicted increased risk of poor Worker Ability Index (WAI) scores (five out of seven studies). There is strong evidence that psychological demands should be considered a predictor for work disability.

\section{(c) Worker control of job}

Seven systematic reviews considered the impact of worker control on work disability. None of the available systematic reviews revealed strong or moderate level evidence. Two high-quality reviews and one lowquality review discussed non-categorized associations. Davey et al. [48] reported that, for workers with mild injury or illness, greater decision latitude predicted reduced risk of unplanned, short-term absences. O'Neil et al. [41] found that low decision latitude predicted reduced work resumption after myocardial infarction. Spelten et al. [42] provided a low-quality review that found, for individuals with cancer, worker discretion over hours worked or amount of work were associated with good return to work outcomes. Limited evidence for a relationship between worker control and work disability was provided by three high-quality reviews. Duijts et al. [44] found that workers with variable psychosocial factors and/or lower decision latitude had increased risk of sick leave of three days or less (adjusted OR: 1.23) and of more than 3 days (adjusted OR = 1.33). These authors also reported similar relationships between increased risk of work absence and low deci- sion authority, low skill discretion, and low work-time control. Hanson and Jensen [49] found low evidence that for workers with low back pain, less decision latitude was associated with increased risk of sick leave of less than three months. Kuijer et al. [50] reported limited evidence that low skill discretion was associated with increased number of days of work absence in workers with chronic low back pain. Finally, insufficient evidence was suggested in a single high-quality review where low decision latitude was linked to increased sick leave in workers with back pain [37].

Two high-quality systematic reviews and one moderate-quality level systematic review considered the impact of job control on work disability. Duijts et al. [44] found weak evidence that, limited job control was associated with increased risk of sick leave of three days or less (adjusted OR $=1.27$ ) and of more than three days (adjusted $\mathrm{OR}=1.28$ ) among individuals with psychosocial health concerns. Hoogendoorn et al. [37] provided a high-quality review looking at this relationship and found insufficient evidence that in cases of low back pain, low job control was associated with increased risk of sick leave. Finally, Michie et al. [46] provided a moderate-quality review suggesting that low job control was associated with increased risk of sickness absence for individuals with psychological ill health. There is strong evidence that a lack of workers' job control should be considered a limited predictor for work disability.

\section{(d) Job strain}

Three high-quality systematic reviews considered the impact of job strain on work disability. Darr and Johns [51] found that for individuals with work stress, increased job strain (i.e., high job demand combined with low job control) was associated with increased absenteeism; in this review, job strain was reported to account for $10 \%$ of the variance in absenteeism. Duijts et al. [44] reported that for individuals with psychosocial health concerns, increased job strain was associated with increased risk of sick leave of three days or less (adjusted OR $=1.20$ ) and of more than three days (crude OR = 1.48). Finally, O'Neil et al. [41] demonstrated that individuals most exposed to job strain experienced reduced work resumption after myocardial infarction. There is strong evidence that job strain should be considered a predictor for work disability.

\section{(e) Job satisfaction}

Five high-quality systematic reviews considered the impact of job satisfaction on work disability. Hoogendoorn et al. [37] reported moderate evidence that lower job satisfaction was related to increased sick leave 
among workers with low back pain. For individuals with psychosocial health concerns, Duijts et al. [44] reported moderate level evidence that low job satisfaction was associated with increased risk of sick leave of more than three days (adjusted OR $=1.93$ ). Davey et al. [48] found that greater job satisfaction was associated with reduced risk of unplanned, short-term work absences in cases of mild illness or injury. Hanson and Jensen [49] identified that in cases of back and neck pain, low job satisfaction predicted increased risk of sick leave. Finally, Truchon et al. [52] found a similar relationship between dissatisfied individuals with chronic low back pain and non-return to work. There is strong evidence that low job satisfaction should be considered a predictor for work disability.

\section{(f) Employment status}

Three systematic reviews considered the impact of employment status on work disability. Two highquality reviews provided weak evidence that part-time status was associated with an increased risk of work disability in workers with rheumatoid arthritis [45,53]. Similarly, a low-quality review found that occasional or non-full-time status was associated with poorer return to work outcomes among workers with workrelated injury [4]. There is moderate evidence that nonfull-time work should be considered a predictor for work disability for workers with rheumatoid arthritis.

(g) Physical demands at work

Eleven systematic reviews considered the impact of physical job demands on work disability. Three high-quality reviews and one moderate-quality review reported strong evidence of a relationship between these variables. De Croon et al. [53] reported that increased physical demands at work were associated with increased risk of work disability for workers with rheumatoid arthritis. Duijts et al. [44] found that high physical demands of work were associated with increased risk for sick leave of more than three days (adjusted OR $=1.66$ ) for people with psychosocial health concerns. Wai et al. [54] found that for workers required to carry loads at work there was a strong relationship between low back pain and heavy physical demands. Similarly, Steenstra et al. [40] found that, for workers with low back pain, heavier work decreased the likelihood of return to work (Pooled RR $=1.40$ ).

Five high quality reviews provided evidence of this association but did not categorize the strength of evidence. Wai et al. [55] provided a high-quality review demonstrating that a requirement to lift loads at work was associated, in a dose response manner, with increased risk of sick leave for individuals with low back pain. Furthermore, Wai et al. [56] reported an association between a requirement for trunk flexion at work and an increased use of sick leave for individuals with low back pain. Hansson and Jensen [49] provided a high-quality review that demonstrated high physical work load among workers with low back pain, and/or poor or rotated working position among workers with neck or back disorders, predicted increased use of sick leave. Detaille et al. [45] provided weak evidence that increased non-sedentary work was associated with an increased risk of work disability in workers with rheumatoid arthritis. Three low quality reviews also provided evidence of this association but did not categorize the strength of evidence. Spelten et al. [42] provided a low-quality review demonstrating that manual labour and greater physical demands at work were associated with poor return to work outcomes for workers with cancer. Two low-quality reviews provided inconsistent evidence of the relationship between physical demands and work disability. van den Berg et al. [47] found that high physical demands at work predicted increased risk of poor Worker Ability Index (WAI) score (four out of seven studies). Shaw et al. [38] similarly suggested there is inconsistent evidence (five out of 11 studies) of a relationship between increased physical demands at work and risk of work disability for individuals with low back pain. There is strong evidence that increased physical job demands should be considered a predictor for work disability.

(h) Supervisor support

Eight systematic reviews considered the impact of supervisory support on work disability. No reviews reported strong or moderate level evidence of a relationship between these variables. Lagerveld et al. [57] provided a high-quality review that found supervisor contact with other professionals (e.g. human resource manager, community health care providers) than occupational physicians was associated with better work participation outcomes, including return to work and work status, for workers with depression. MacEachen et al. [58] provided a second high-quality review demonstrating that, in situations of musculoskeletal and pain-related injury, supervisory monitoring, advocacy and early communication with injured workers was associated with increased likelihood of return to work, except when the employee-manager relationship was poor (i.e. performance problems or preinjury workplace relations problems. Kuijer et al. [50] found that, among workers with low back pain, lower employer response to illness/injury predicted an in- 
crease in absenteeism. Cote and Coutu [59] reported that for workers with musculoskeletal pain, greater experiences of mistrust predicted poorer workplace outcomes. Finally, the third high-quality review on this topic found that supervisory respect and consideration for employees were associated with reduced risk of unplanned, short-term work absences among workers with a mild injury or illness [48].

Additional evidence for this relationship was provided by two moderate-quality reviews and one lower quality review. Specifically, Blank et al. [60] found improved work participation outcomes for workers with mental disorders in situations of increased supervisory contact with professionals other than occupational physicians, and increased supervisor communication with the respective employee. Steenstra et al. [40] provided a moderate-quality review demonstrating that high supervisory support increased the likelihood of RTW for workers with low back pain. Finally, Fadyl et al. [43] found that in cases of work-related injury, high supervisory support was associated with increased work ability. There is strong evidence that a lack of supervisory support should be considered a predictor for work disability.

(i) Leadership quality

Three systematic reviews considered the impact of leadership quality on work disability. Kuoppala et al. [61] provided a high-quality review demonstrating weak-moderate evidence (depending on leadership style) that good quality leadership led to increased job well-being and reduced likelihood of sick leave and disability pension. Davey et al. [48] also provided a high-quality review that demonstrated very weak evidence of a relationship between leadership quality and increased job well-being for workers with mild injury or illness. Finally, Michie et al. [46] provided a moderate quality review that demonstrated unsupportive management style was associated with increased risk of sickness absence in individuals with psychological ill health. There is moderate evidence that poor leadership quality should be considered a predictor for work disability.

\subsubsection{Organizational level}

\section{(a) Fairness}

Two high-quality studies considered the impact of workplace fairness (perceived injustice) on work disability. Specifically, Duijts et al. [44] found that, with respect to individuals with psychosocial health concerns, a feeling of not being treated fairly in the workplace was associated with increased risk of sick leave
Table 6

Modifiable workplace factors (inconsistent/insufficient)

\begin{tabular}{ll}
\hline Inconsistent & Insufficient \\
\hline Compensation and insurance & Workplace physical environment \\
level [45,48,58,60] & {$[43,47]$} \\
Intervention Approaches [40, & Job stress [61] \\
$43,46,58,62]$ & \\
& Staff training [46] \\
& Goodwill in workplace [58] \\
& Union involvement [58] \\
& Health systems factors [40] \\
& Employer barriers [62]* \\
& Workplace staffing [48] \\
& Treatment Communication [58] \\
\hline
\end{tabular}

for three days or less (adjusted OR $=1.19$ ) and of more than three days (adjusted OR =1.30). Davey et al. [48] similarly reported that feelings of distributive justice were associated with reduced risk of unplanned, shortterm work absences among individuals with mild illness or injury. There is moderate evidence that lack of workplace fairness (perceived injustice) should be considered a predictor for work disability.

(b) Perceptions regarding absenteeism

Two systematic reviews considered the impact of absenteeism norms on work disability. Davey et al. [48] provided a high-quality review that found greater perceived absence norms were associated with increased risk of unplanned, short-term work absences among individuals with mild injury or illness. Michie et al. [46] provided a moderate quality review that found workplace tolerance of absenteeism was associated with increased risk of taking sick leave among individuals with psychological health concerns. There is weak evidence that increased absenteeism tolerance should be considered a predictor for work disability.

(c) Reorganizational stress

Two systematic reviews considered the impact of reorganizational stress on work disability. Duijts et al. [44] provided a high-quality review demonstrating the presence of reorganization within the workplace was associated with an increased risk of sick leave of three days or less (adjusted OR $=1.32$ ) and of more than three days (crude OR $=1.09$ ) for individuals with psychosocial health concerns. Blank et al. [60] provided a moderate-quality review that similarly demonstrated reorganizational stress was associated with a decreased likelihood of return to work for workers with mental disorders. There is weak evidence that reorganizational stress should be considered a predictor for work disability.

(d) Managerial involvement

Two systematic reviews considered the impact of managerial influence on work disability. Davey et 
al. [48] provided a high-quality review and found that managerial influence and personnel resources were associated with reduced risk of unplanned, short-term work absences for workers with mild illness or injury. Similarly, Lidal et al. [62] provided a low-quality review that found manager support and advocacy for worker involvement with compensation or healthcare systems was associated with better return to work outcomes for individuals with spinal cord injury. There is weak evidence that lack of managerial involvement should be considered a predictor for work disability.

\section{(e) Time to treatment}

Two systematic reviews considered the impact of time to treatment on work disability. Detaille et al. [45], in a high-quality review, found weak evidence that lesser time to treatment reduced the risk of work disability in workers with rheumatoid arthritis. Turner et al. [4] completed a low-quality review and found that greater time to treatment was associated with poorer return to work outcomes for individuals with work related injury. There is weak evidence that time to treatment should be considered a predictor of work disability.

\section{Discussion}

\subsection{Review of findings}

For modifiable workplace factors, our synthesis indicated that work disability could be predicted from a lack of social support, increased job strain, increased psychological job demand, low job satisfaction, increased physical job demands, and a lack of supervisory support. Of these variables, lack of social and supervisory support, increased physical demands at work, together with increased psychological demand, all demonstrated strong evidence across different types of illnesses and/or injuries. In contrast, job strain was found to be a strong predictor specifically for psychosocial, stress, and cardiovascular issues, and lack of job control was demonstrated only for individuals with psychosocial or psychological health issues and low back pain. Similarly, job satisfaction had strong evidentiary support as a predictor primarily for mild illness or injury, psychosocial health issues, and back and neck pain. In support of the present results, the findings from our study are consistent with one of the primary occupational stress models described in the literature, Karasek and Theorell's Demand-ControlSupport Model [63-67], in that the primary factors identified here include aspects of job demand, job control and social support within the workplace.

The present results also indicate moderate evidence that work disability could be predicted from non fulltime work, lack of job control, poor leadership quality, lack of workplace fairness (perceived injustice), and lack of managerial involvement. Of these variables, poor leadership quality had evidence available across a wide variety of injuries and/or illnesses. In contrast, non-full-time work was demonstrated only for individuals with rheumatoid arthritis and work-related injury, lack of fairness was demonstrated only for individuals with psychosocial health concerns and individuals with mild illness or injury, and lack of managerial involvement was demonstrated only for individuals with mild illness or injury and spinal cord injury.

Other data categorized as weak, inconsistent and/or insufficient evidence provide areas for future research. Although currently available information does not support the factors in these categories as having a large impact on return to work, future research may provide more information that significantly alters the placement of these factors within these types of evidentiary categories. In particular, many factors may have been included in one of three categories (weak, inconsistent or insufficient evidence), not because a relationship does not exist, but rather, because little research has investigated the factor, resulting in an inadequate empirical base for evaluation.

\subsection{Implications}

The present data suggest that employers and other work disability stakeholders, attempting to predict disability ought to recognize that risk for disability is likely to increase in work environments with limited social and supervisory support, heightened physical and psychological demands, and poor leadership quality; all these factors conceptually representing various modifiable dimensions of occupational stress. Given current evidence, workplace stakeholders should therefore consider these factors as characteristics that can be potentially altered, albeit not necessarily without challenges associated with multi-level organizational change. Many of our workplace stakeholders expressed concern that often workplace interventions are created as a result of a presumed "good idea" without consideration or reflection on risk or protective factors contributing to work absence. As a result, the present data may be useful as a starting point for stakeholders considering potential factors that may be contribut- 
ing to unnecessary work disability, and/or when planning interventions to address unnecessary work absence. Consideration of these factors may assist stakeholders in decreasing disability rates and costs, improve strategic and operational planning, and enhance productivity outcomes.

\subsection{Conclusions}

The primary intent of this study was to create evidence-based and meaningful data that was directed by, and pragmatically useful to, all members of an Academic and Community Partnership. The active engagement of community stakeholders in the creation of the synthesis questions, search strategy, abstraction process and translation of information contributed greatly to the framing of the synthesis, understanding of the relevance and applicability of findings in real life work environment, as well as the way of reporting of results. Through this multi-step process of stakeholder engagement, data abstraction and synthesis, we created information relevant for participating stakeholders to consider potential modifiable workplace factors that may be contributing to difficulty in returning to work and sustaining employment. From this interactive and iterative process, lessons were learned by all participants. Researchers and workplace stakeholders gained an appreciation of the expertise and experience of others, learned more about research interests and needs of participating organization partners, and worked together to ensure uptake, understanding and utilization of the data.

The present article addresses a gap in the literature by considering the needs of knowledge translation through the lens of an academic-community partnership. Specifically, the present paper contributes to the available literature by taking an integrative approach to modifiable workplace risk and protective factors associated with work absence across common health conditions and injuries.

Not unexpectedly, the modifiable organizational factors most consistently identified as potentially predictive of work disability across health conditions and injuries, namely low social and supervisory support, increased physical and psychological demands and poor leadership quality, coincide with classic conceptual dimensions of occupational stress. Reduction of occupational stress, for its own sake, is rarely a stand-alone business goal. However, recognition that the very organizational factors contributing to organizational stress can result in increased disability risk and decreased productivity may encourage employers to consider organizational changes to reduce unnecessary occupational stress. This new found awareness might encourage the work disability stakeholders to promote efforts to modify these key disability-predictive organizational factors in existing workplaces, and to design or re-design work environment accordingly.

\section{Acknowledgments}

This paper is dedicated to Dr. Rick Iverson, who was a co-author on this manuscript. Dr. Iverson passed away suddenly on May 3, 2012 and participated in academic community stakeholder partnership meetings, search strategies, categorization of factors and the discussion section of this paper.

\section{Financial disclosure}

This research was supported by a competitive research grant from WorkSafeBC through the focus on tomorrow program, and Healthcare Benefits Trust, a not-for-profit health and welfare trust. Neither grantor had any editorial control over manuscripts submitted for publication.

\section{References}

[1] Statistics Canada. Work Absence Rates. Ottawa, ON: Minister of Industry; 2011 May 1. Report No.: Catalogue no. 71-211$\mathrm{X}$

[2] Health Canada. Economic Burden of Illness in Canada, 1998. Ottawa, ON: Minister of Public Works and Government Services Canada; 2002.

[3] Health Council of Canada. Why Health Care Renewal Matters: Learning from Canadians with Chronic Health Conditions. Toronto, ON: Health Council of Canada; 2007 Jan 12.

[4] Turner JA, Franklin G, Turk DC. Predictors of chronic disability in injured workers: A systematic literature synthesis. Am J Ind Med 2000 Dec;38(6):707-22.

[5] Schultz IZ, Gatchel RJ. Research and Practice Directions in Risk for Disability Prediction and Early Intervention. In: Schultz IZ, Gatchel RJ, editors. Handbook of Complex Occupational Disability Claims. Early identification, intervention and prevention. New York: Springer; 2008. p. 523-39.

[6] White MI, Richman J, Kerr S, Toro Posada S. Enhancing Stakeholders' Knowledge and Skills in Disability Prevention, Detection and Management. Vancouver, BC: Canadian Institute for the Relief of Pain and Disability; 2004.

[7] Dewa CS, Lin E, Kooehoorn M, Goldner E. Association of chronic work stress, psychiatric disorders, and chronic physical conditions with disability among workers. Psychiatr Serv 2007 May;58(5):652-8. 
[8] Dewa CS, Lin E. Chronic physical illness, psychiatric disorder and disability in the workplace. Soc Sci Med 2000 Jul; 51(1):41-50.

[9] Melhorn JM, Lazarovic J, Roel WK. Do we have a disability epidemic? In: Schultz IZ, Gatchel RJ, editors. Handbook of Complex Occupational Disability Claims. Early identification, intervention and prevention. New York: Springer; 2008. p. 7-24.

[10] Guzman J, Yassi A, Baril R, Loisel P. Decreasing occupational injury and disability: the convergence of systems theory, knowledge transfer and action research. Work 2008; 30(3):229-39.

[11] Loisel P, Durand MJ, Baril R, Gervais J, Falardeau M. Interorganizational collaboration in occupational rehabilitation: Perceptions of an interdisciplinary rehabilitation team. J Occup Rehabil 2005 Dec;15(4):581-90.

[12] Franche RL, Baril R, Shaw W, Nicholas M, Loisel P. Workplace-based return-to-work interventions: optimizing the role of stakeholders in implementation and research. J Occup Rehabil 2005 Dec;15(4):525-42.

[13] Loisel P, Buchbinder R, Hazard R, Keller R, Scheel I, van TM, et al. Prevention of work disability due to musculoskeletal disorders: The challenge of implementing evidence. J Occup Rehabil 2005 Dec;15(4):507-24.

[14] Frank JW, Brooker AS, DeMaio SE, Kerr MS, Maetzel A, Shannon HS, et al. Disability resulting from occupational low back pain. Part II: What do we know about secondary prevention? A review of the scientific evidence on prevention after disability begins. Spine 1996 Dec 15;21(24):2918-29.

[15] White MI, Kube D, Petruniak J, Myette L, King L, Johnston $\mathrm{R}$, et al. Best Practices Leadership Summit on Disability Prevention. Vancouver, BC: Canadian Institute for the Relief of Pain and Disability; 2007.

[16] Arthur JB, Jelf GF. The effects of gainsharing on grievance rates and absenteeism over time. Journal of Labor Research 1999;20(1):133-45

[17] Barling J, Kelloway EK, Iverson RD. High-quality work, job satisfaction, and occupational injuries. J Appl Psychol 2003 Apr;88(2):276-83.

[18] Zacharatos A, Barling J, Iverson RD. High-performance work systems and occupational safety. J Appl Psychol 2005 Jan;90(1):77-93

[19] MacDermid JC, Geldart S, Williams RM, Westermorland ML, Lin CY. Work organization and health: A qualitative study of the perceptions of workers. Work 2008;30:241-54.

[20] AWCBC. Key Statistical Measures for 2006. Association of Workers' Compensation Boards of Canada (AWCBC); 2008.

[21] Townsend AL, Ishler KJ, Vargo EH, Shapiro BM, Pitorak EF, Matthews CR. The FACES Project: An academic-community partnership to improve end-of-life care for families. J Gerontol Soc Work 2007;50(1-2):7-20.

[22] Ofili E, Igho-Pemu P, Lapu-Bula R, Quarshie A, Obialo C, Thomas C, et al. The Community Physicians' Network (CPN): An academic-community partnership to eliminate healthcare disparities. Ethn Dis 2005;15(4 Suppl 5):S5-S7.

[23] Trauth JM, Jernigan J, Myers SM, Potter M, Fedor K, Procopio J, et al. Developing an academic-community partnership in the context of Pennsylvania's State Health Improvement Plan. Public Health Rep 2003 Mar;118(2):169-74.

[24] Berkowitz B. Collaboration for health improvement: Models for state, community, and academic partnerships. J Public Health Manag Pract 2000 Jan;6(1):67-72.

[25] Hall KL, Stokols D, Moser RP, Taylor BK, Thornquist MD, Nebeling LC, et al. The collaboration readiness of transdisci- plinary research teams and centers findings from the National Cancer Institute's TREC Year-One evaluation study. Am J Prev Med 2008 Aug;35(2 Suppl):S161-S172.

[26] Stokols D, Hall KL, Taylor BK, Moser RP. The science of team science: Overview of the field and introduction to the supplement. Am J Prev Med 2008 Aug;35(2 Suppl):S77-S89.

[27] Hall KL, Feng AX, Moser RP, Stokols D, Taylor BK. Moving the science of team science forward: collaboration and creativity. Am J Prev Med 2008 Aug;35(2 Suppl):S243-S249.

[28] Masse LC, Moser RP, Stokols D, Taylor BK, Marcus SE, Morgan GD, et al. Measuring collaboration and transdisciplinary integration in team science. Am J Prev Med 2008 Aug;35(2 Suppl):S151-S160.

[29] Feinberg ME, Bontempo DE, Greenberg MT. Predictors and level of sustainability of community prevention coalitions. Am J Prev Med 2008 Jun;34(6):495-501.

[30] Finding What Works in Health Care: Standards for Systematic Reviews. Washington, DC: Institute of Medicine of the National Academies; 11 A.D. Mar 23.

[31] Shea BJ, Grimshaw JM, Wells GA, Boers M, Andersson N, Hamel C, et al. Development of AMSTAR: A measurement tool to assess the methodological quality of systematic reviews. BMC Med Res Methodol 2007;7:10.

[32] VonVille H. Excel workbookto track systematic review search results. 2011. Houston, Texas, The University of Texas School of Public Health. Online Source retreived January 25, 2013 https://sph.uth.edu/content/uploads/2010/07/Tracking_Searc hes2.xls.

[33] Moher D, Liberati A, Tetzlaff J, Altman DG. Preferred reporting items for systematic reviews and meta-analyses: the PRISMA statement. J Clin Epidemiol 2009 Oct;62(10):100612.

[34] Slavin RE. Best evidence synthesis: An intelligent alternative to meta-analysis. J Clin Epidemiol 1995 Jan;48(1):9-18.

[35] Carroll LJ, Cassidy JD, Peloso PM, Giles-Smith L, Cheng CS, Greenhalgh SW, et al. Methods for the best evidence synthesis on neck pain and its associated disorders: The bone and joint decade 2000-2010 task force on neck pain and its associated disorders. Spine (Phila Pa 1976 ) 2008 Feb 15;33(4 Suppl): S33-S38.

[36] Franche RL, Cullen K, Clarke J, Irvin E, Sinclair S, Frank J. Workplace-based return-to-work interventions: a systematic review of the quantitative literature. J Occup Rehabil 2005 Dec;15(4):607-31.

[37] Hoogendoorn WE, van Poppel MN, Bongers PM, Koes BW, Bouter LM. Systematic review of psychosocial factors at work and private life as risk factors for back pain. Spine (Phila $\mathrm{Pa}$ 1976) 2000 Aug;25(16):2114-25.

[38] Shaw WS, Pransky G, Fitzgerald TE. Early prognosis for low back disability: intervention strategies for health care providers. Disabil Rehabil 2001 Dec;23(18):815-28.

[39] Hartvigsen J, Lings S, Leboeuf-Yde C, Bakketeig L. Psychosocial factors at work in relation to low back pain and consequences of low back pain; a systematic, critical review of prospective cohort studies. Occup Environ Med 2004 Jan; 61(1):e2.

[40] Steenstra IA, Verbeek JH, Heymans MW, Bongers PM. Prognostic factors for duration of sick leave in patients sick listed with acute low back pain: A systematic review of the literature. Occup Environ Med 2005 Dec;62(12):851-60.

[41] O’Neil A, Sanderson K, Oldenburg B. Depression as a predictor of work resumption following myocardial infarction (MI): A review of recent research evidence. Health Qual Life Outcomes 2010;8:95. 
[42] Spelten ER, Sprangers MA, Verbeek JH. Factors reported to influence the return to work of cancer survivors: A literature review. Psychooncology 2002 Mar;11(2):124-31.

[43] Fadyl JK, McPherson KM, Schluter PJ, Turner-Stokes L. Factors contributing to work-ability for injured workers: Literature review and comparison with available measures. Disabil Rehabil 2010;32(14):1173-83.

[44] Duijts SF, Kant I, Swaen GM, van den Brandt PA, Zeegers MP. A meta-analysis of observational studies identifies predictors of sickness absence. J Clin Epidemiol 2007 Nov; 60(11):1105-15.

[45] Detaille SI, Heerkens YF, Engels JA, van der Gulden JW, van Dijk FJ. Common prognostic factors of work disability among employees with a chronic somatic disease: A systematic review of cohort studies. Scand J Work Environ Health 2009 Jul;35(4):261-81.

[46] Michie S, Williams S. Reducing work related psychological ill health and sickness absence: a systematic literature review. Occup Environ Med 2003 Jan;60(1):3-9.

[47] van den Berg TI, Elders LA, de Zwart BC, Burdorf A. The effects of work-related and individual factors on the Work Ability Index: A systematic review. Occup Environ Med 2009 Apr;66(4):211-20.

[48] Davey MM, Cummings G, Newburn-Cook CV, Lo EA. Predictors of nurse absenteeism in hospitals: A systematic review. J Nurs Manag 2009;17(3):312-30.

[49] Hansson T, Jensen I. Swedish Council on Technology Assessment in Health Care (SBU). Chapter 6. Sickness absence due to back and neck disorders. Scand J Public Health Suppl 2004; 63:109-51.

[50] Kuijer W, Groothoff JW, Brouwer S, Geertzen JH, Dijkstra PU. Prediction of sickness absence in patients with chronic low back pain: A systematic review. J Occup Rehabil 2006 Sep;16(3):439-67.

[51] Darr W, Johns G. Work strain, health, and absenteeism: A meta-analysis. J Occup Health Psychol 2008;13(4):293-318.

[52] Truchon M, Fillion L. Biopsychosocial determinants of chronic disability and low-back pain: a review. J Occup Rehabil 2000;10(2):117-42.

[53] De Croon EM, Sluiter JK, Nijssen TF, Dijkmans BA, Lankhorst GJ, Frings-Dresen MH. Predictive factors of work disability in rheumatoid arthritis: A systematic literature review. Ann Rheum Dis 2004 Nov;63(11):1362-7.

[54] Wai EK, Roffey DM, Bishop P, Kwon BK, Dagenais S. Causal assessment of occupational carrying and low back pain:
Results of a systematic review. Spine J 2010 Jul;10(7):628-38.

[55] Wai EK, Roffey DM, Bishop P, Kwon BK, Dagenais S. Causal assessment of occupational lifting and low back pain: Results of a systematic review. Spine J 2010 Jun;10(6):554-66.

[56] Wai EK, Roffey DM, Bishop P, Kwon BK, Dagenais S. Causal assessment of occupational bending or twisting and low back pain: Results of a systematic review. Spine J 2010 Jan;10(1):76-88.

[57] Lagerveld SE, Bultmann U, Franche RL, van Dijk FJ, Vlasveld MC, van der Feltz-Cornelis CM, et al. Factors associated with work participation and work functioning in depressed workers: A systematic review. J Occup Rehabil 2010 Sep;20(3):275-92.

[58] MacEachen E, Clarke J, Franche RL, Irvin E. Systematic review of the qualitative literature on return to work after injury. Scand J Work Environ Health 2006 Aug;32(4):257-69.

[59] Cote D, Coutu MF. A critical review of gender issues in understanding prolonged disability related to musculoskeletal pain: How are they relevant to rehabilitation? Disabil Rehabil 2010;32(2):87-102.

[60] Blank L, Peters J, Pickvance S, Wilford J, Macdonald E. A systematic review of the factors which predict return to work for people suffering episodes of poor mental health. J Occup Rehabil 2008;18(1):27-34.

[61] Kuoppala J, Lamminpaa A, Liira J, Vainio H. Leadership, job well-being, and health effects - a systematic review and a meta-analysis. J Occup Environ Med 2008 Aug;50(8):904-15.

[62] Lidal IB, Huynh TK, Biering-Sorensen F. Return to work following spinal cord injury: a review. Disabil Rehabil 2007 Sep 15;29(17):1341-75.

[63] Karasek RA. Job demands, job decision latitude, and mental strain: Implications for job design. Administrative Science Quarterly 1979 Jan 1;24:285-308.

[64] Karasek RA, Theorell T. Healthy Work: Stress, Productivity and the Reconstruction of Working Life. New York: Basic Books; 1990.

[65] Karasek RA. Stress at work: An integrative approach. New Solut 1994 Jul;4(4):28-35.

[66] Theorell T, Karasek RA. Current issues relating to psychosocial job strain and cardiovascular disease research. J Occup Health Psychol 1996 Jan;1(1):9-26.

[67] Karasek RA. Demand/Control Model: A social, emotional, and physiological approach to stress risk and active behaviour development. In: Stellman JM, editor. Encyclopaedia of occupational health and safety. Geneva: ILO; 1998. p. 6-34. 